\title{
Comparative clinical trial of diazepam with other conventional drugs in tetanus
}

\author{
NALINI T. VASSA \\ M.D. \\ V. H. YAJNIK \\ M.D. \\ K. R. JosHI \\ M.B.B.S.
}

\author{
H. V. DoshI \\ M.D. \\ S. S. ShaH \\ M.D. \\ S. H. Patel \\ M.B.B.S.
}

\section{M.P. Shah Medical College and Irwin Group of Hospitals, Jamnagar, Gujarat State, India}

\begin{abstract}
Summary
Results of therapeutic trial of diazepam in tetanus are presented. The trial included 200 cases of tetanus167 non-neonates and thirty-three neonates. The patients were divided into two groups and were matched as regards age, sex and severity of the disease. The cases of group I received standard treatment while the cases of group II received diazepam in addition. Over-all mortality in group I was $54 \%$ and in group II, $26 \%$. The results were statistically significant in non-neonates and in severe degree of tetanus. The drug was well tolerated and side effects were not observed.
\end{abstract}

\section{Introduction}

Tetanus is still a major medical problem in the developing countries where it is responsible for the considerable mortality in spite of the progress in prophylaxis and therapeutics. Death in these cases is commonly due to complications secondary to muscular rigidity and spasms of voluntary muscles. Spasms are painful and, if persistent, exhaust the patient and death may be due to resultant exhaustion or apnoea following sudden laryngeal spasm. The ideal drug should be one that relieves the muscle spasms without interfering with respiration and circulation, and should induce prompt sedation without loss of consciousness, and serious side effects (Weinberg, 1964). Commonly used drugs such as the central nervous system depressants paraldehyde and barbiturates; neuromuscular blocking agents, such as curare and curare-like compounds; and drugs acting at the spinal internuncial level, such as mephenesin, meprobamate and chlorpromazine, are used with variable success. Recently, diazepam has been found useful in the treatment of tetanus. Diazepam is a tranquillizer and muscle-relaxant of the 1,4-benzodiazepine group. In quite a few studies diazepam was used either in combination with other sedatives (Weinberg, 1964; Hendrickse and Sherman, 1965, 1966; Femi-Pearse, 1966; Das, Gupta and De, 1967) or alone (Grewal and Sharma, 1969; Van Heijst, 1970) with considerable reduction in mortality as well as morbidity.

The present study was undertaken to evaluate comparatively in combination with (1) phenobarbitone; (2) chlorpromazine; (3) paraldehyde; (4) with a combination of all three.

\section{Material and methods}

Two hundred consecutive cases of tetanus admitted to the Infectious Diseases Unit of Irwin Group of Hospitals, Jamnagar, from August 1971 to May 1973, were included in the study. The diagnosis of tetanus was based on the characteristic clinical findings of the disease. The study included neonates and non-neonates. All the cases included in the study underwent thorough clinical examination after noting the age and sex. Special attention was paid to determine the suspected portal of entry, incubation and onset period. The severity of the illness was graded according to the classification proposed by Patel and Joag (1959). The patients were put in a dark and quiet room and were continuously observed for the development of newer signs and complications. All non-neonate cases received i.m. injection of 20,000 units ATS and neonates 10,000 units. In addition they received penicillin and proper management of the wound. Ryles tube feeding, i.v. fluid and vasopressor drugs were administered when necessary. Complications were dealt with appropriately. The patients were divided into two equal groups: I and II, and they were matched as regards 
age, sex and severity of the disease. Group I patients received phenobarbitone, chlorpromazine and paraldehyde. Group II patients received oral diazepam in addition to the above treatment. Paraldehyde was used at the time of admission when the patient had severe spasms, and in all the cases during treatment whenever needed. The dose of paraldehyde was 1-2 $\mathrm{ml}$ in neonates, 4-5 $\mathrm{ml}$ in infants and children and $7-10 \mathrm{ml}$ in adults, given deep i.m. Phenobarbitone and chlorpromazine were given 4, 6 and 8-hourly in cyclical fashion according to the requirement. Adults were given phenobarbitone in doses of $100-200 \mathrm{mg}$ and chlorpromazine was given in doses of $25-50 \mathrm{mg}$. Children were given orally one half, and infants one quarter of the adult doses. In mild cases, the drugs were administered orally and in severe cases they were administered parenterally. In both the groups, the higher dosage was given to grades IV and V and the lower dosage to grades I, II and III.

\section{Observation}

Two hundred consecutive cases of tetanus were included in the present study. Age and sex of the patients in two groups are shown in Table 1. There were 132 male and sixty-eight female cases. Of these, thirty-three were neonates and 167 non-neonates. The majority of the cases were aged 0-10 years. Table 2 shows the portal of entry of infection in the two groups. There was no significant difference in age, sex and portal of entry of infection between the groups. Table 3 shows the distribution of grades in the two groups, and mortality in relation to the grades of the severity of the disease. It is apparent that the mortality rate in both the groups had a direct correlation to the grades of the disease, being progressively higher from grade I to $\mathrm{V}$, however, the mortality in group II was $26 \%$ and in group I it was $54 \%$. Table 4 shows the mortality rate in relation to the age of the patient. Table 5 shows various complications in two groups. Laryngeal spasm, hyperpyrexia and pulmonary oedema were observed in

TABLE 1. Showing age and sex distribution in two groups

\begin{tabular}{|c|c|c|c|c|c|c|}
\hline \multirow[b]{2}{*}{ Age } & \multicolumn{3}{|c|}{ Group I } & \multicolumn{3}{|c|}{ Group II } \\
\hline & Male & Female & Total & Male & Female & Total \\
\hline $\begin{array}{l}\text { Neonates } \\
1 \text { month- }\end{array}$ & 14 & 03 & 17 & 11 & 05 & 16 \\
\hline 10 years & 24 & 10 & 34 & 27 & 09 & 36 \\
\hline $11-20$ & 09 & 07 & 16 & 07 & 07 & 14 \\
\hline $21-30$ & 10 & 04 & 14 & 08 & 08 & 16 \\
\hline $31-40$ & 04 & 04 & 08 & 03 & 04 & 07 \\
\hline $41-50$ & 03 & 02 & 05 & 06 & 00 & 06 \\
\hline $\begin{array}{l}51-60 \\
61 \text { and }\end{array}$ & 03 & 00 & 03 & 01 & 01 & 02 \\
\hline above & 01 & 02 & 03 & 01 & 02 & 03 \\
\hline Total & 68 & 32 & 100 & 64 & 36 & 100 \\
\hline
\end{tabular}

TABLE 2. Showing the portal of entry of infection in two groups

\begin{tabular}{lcc}
\hline Portal of entry & Group I & Group II \\
\hline Umbilicus & 17 & 16 \\
Middle ear & 18 & 22 \\
Injury and sepsis & 39 & 37 \\
Post partum & 08 & 08 \\
Post operative & 01 & 02 \\
Undetected & 17 & 15 \\
Total & 100 & 100 \\
\hline
\end{tabular}

TABLE 3. Showing mortality in relation to the grades of severity of the disease in two groups

\begin{tabular}{rccccc}
\hline & \multicolumn{2}{c}{ Group I } & & \multicolumn{2}{c}{ Group II } \\
\cline { 2 - 3 } \cline { 5 - 6 } Grade & $\begin{array}{c}\text { No. of } \\
\text { cases }\end{array}$ & Mortality & & $\begin{array}{c}\text { No. of } \\
\text { cases }\end{array}$ & Mortality \\
\hline I & 05 & 00 & & 04 & 00 \\
II & 16 & 02 & & 12 & 00 \\
III & 20 & 05 & & 20 & 03 \\
IV & 33 & 25 & & 38 & 10 \\
V & 26 & 22 & & 26 & 13 \\
Total & 100 & 54 & & 100 & 26 \\
\hline
\end{tabular}

Difference in mortality in grade I, II and III, in two groups is insignificant.

By applying standard of difference between two mortality $\bigcirc$ proportion: ratio for grade IV is 4.79 , hence it is highlyo significant at $99.99 \%$ limit; ratio for grade $V$ is 2.86 , hence it is highly significant at $95 \%$ limit.

TABLE 4. Showing mortality in relation to the age in two groups

\begin{tabular}{lccccc}
\hline & \multicolumn{2}{c}{ Group I } & & \multicolumn{2}{c}{ Group II } \\
\cline { 2 - 3 } \cline { 5 - 6 } $\begin{array}{c}\text { Age } \\
\text { (years) }\end{array}$ & $\begin{array}{c}\text { No. of } \\
\text { cases }\end{array}$ & Mortality & & $\begin{array}{c}\text { No. of } \\
\text { cases }\end{array}$ & Mortality \\
\hline $\begin{array}{l}\text { Neonates* } \\
\text { 1 month to }\end{array}$ & 17 & 11 & 16 & 06 \\
10 years & 34 & 19 & & 36 & 07 \\
$11-20$ & 16 & 09 & & 14 & 05 \\
$21-30$ & 14 & 06 & & 16 & 03 \\
$31-40$ & 08 & 03 & & 07 & 02 \\
$41-50$ & 05 & 02 & & 06 & 02 \\
$51-60$ & 03 & 02 & & 02 & 00 \\
61 and & 03 & 02 & & 03 & 01 \\
above & 03 & 54 & 100 & 26 \\
Total & 100 & 54 &
\end{tabular}

* By applying standard of difference between two mortality proportion in neonates is statistically not significant as the ratio is 1.62 which is less than 2 .

eighteen, eight and eight cases respectively in group II, while these were observed in thirty-four, twelve and twenty cases respectively in group I. The drug was well tolerated. Respiratory depression, ataxia and behavioural changes were looked for but no side effects were observed in any patient. 
TABLE 5. Showing various complications in two groups

\begin{tabular}{lcc}
\hline Coinplications & Group I & Group II \\
\hline Laryngeal spasms and & & \\
respiratory arrest & 34 & 18 \\
Pulmonary oedema & 20 & 08 \\
Hyperpyrexia & 12 & 08 \\
Injection abscess & 05 & 03 \\
Pneumonia & 03 & 00 \\
Cardiac arrest & 00 & 01 \\
Late ATS reaction & 00 & 01 \\
\hline
\end{tabular}

\section{Discussion}

Diazepam (7-chloro-1,3-dihydro-1-methyl-5phenyl-2H-1, 4-benzo-diazepine-2-1) is a derivative of benzodiazepine. The benzodiazepines are sedatives, anticonvulsants and skeletal muscle relaxants (Brown and Werner, 1954; Bradley and Key, 1958). Diazepam is considered to act at the spinal internuncial level (Weinberg, 1964), the ascending reticular activating system and amygdala (Hernandez-Peon et al., 1964; Arrigo, Jann and Tonali, 1965). It is reported to be five times as potent as chlordiazepoxide as a tranquillizer and muscle relaxant (Randall et al., 1961). This drug has recently been used in the treatment of many spastic conditions, with promising results. These facts suggested that diazepam might be of value in the management of tetanus. The first successful treatment of tetanus with the use of diazepam was reported by Weinberg in 1964. Since then the drug has been found to be effective, in controlling spasms, trismus and rigidity and thereby reducing the frequency of complications and mortality in tetanus, by various workers (Hendrickse and Sherman, 1966; Femi-Pearse, 1966; Das et al., 1966; Grewal and Sharma, 1969). In the present series patients treated with diazepam started feeling better subjectively from the early stages of the treatment and as seen in Table 5, incidence of complications in group II was much less than in group I.

There was good correlation between severity of the disease and mortality in both the groups. The mortality increased progressively with the severity ( $\alpha^{2}$ was 39.83 and 14.66 in group I and II respectively, while $t<0.001$ for both the groups). There was no significant difference in mortality in the two groups in grades I, II and III, whereas of the sixtyfour cases of grades IV and V in group II, twentythree $(35.9 \%)$ died, and of the fifty-nine cases of grades IV and V in group I, forty-seven (79.6\%) died (this difference is statistically significant). However, Hendrickse and Sherman (1966) treated forty-nine cases of severe tetanus with phenobarbitone and chlorpromazine, and thirty-nine similar cases with phenobarbitone, chlorpromazine and diazepam with about $66 \%$ mortality in both groups. Other workers mentioned overall reduction in mortality with the use of diazepam but did not examine the mortality rate in relation to the severity of the tetanus (FemiPearse, 1966; Grewal and Sharma, 1969).

The mortality in non-neonates in the present series was $23.8 \%$ in group II and $51.8 \%$ in group I (standard of difference between the two groups is 4.22 which is highly significant at $99.99 \%$ limit. Grewal and Sharma (1969) noted $27.5 \%$ mortality in their 160 non-neonates treated with diazepam alone. Das et al. (1967) also reported 30\% mortality out of ten cases of tetanus. Femi-Pearse (1966), who treated forty-two cases using diazepam in combination with the standard regime, recorded six deaths $(14.3 \%)$. Hendrickse and Sherman (1966) also observed a $26 \%$ (six out of twenty-three cases) mortality in older children given diazepam, compared with a $50 \%$ (eleven out of twenty-two cases) mortality in those not given diazepam.

Post-partum tetanus carries a high mortality rate (Laha and Vaishya, 1965). Although the number of post-partum tetanus cases in both the groups of the present series was too small to draw any conclusion, the mortality rate in group II was $\mathbf{3 7 . 5 \%}$ as compared with $62 \%$ in group I.

The prognosis for patients with tetanus neonatorum is grave and the reported mortality extends up to $90 \%$. Good results have been reported by Grewal and Sharma (1969) who had a $25 \%$ mortality in forty infants treated with diazepam alone, whereas Hendrickse and Sherman (1966) treated fifty-three neonates with diazepam, phenobarbitone and chlorpromazine, and fifty-one cases with phenobarbitone and chlorpromazine, and had a $55 \%$ mortality in both groups. However, they were of the opinion that diazepam was a good adjuvant to relieve tonic muscle spasms. In the present study, the mortality in the neonatal tetanus in group II was $37.5 \%$ (six of sixteen cases) compared with $64.7 \%$ (eleven out of seventeen cases) in group I (Table 4). However, these results are statistically not significant enough to draw any conclusion because of the limited number, of cases in each group.

Respiratory depression is an undesirable side effect in the management and has not been observed with diazepam therapy (Femi-Pearse, 1966; Grewal and Sharma, 1969). No serious side effects have yet been reported. The most frequent side effects are drowsiness, ataxia and lethargy (Domino, 1965). Femi-Pearse (1966) observed behavioural changes such as euphoria, talkativeness, indecorous behaviour, disorientation and hallucination. We did not notice any of these side effects. Neither did Hendrickse and Sherman (1966) nor Grewal and Sharma (1969) report any untoward effects. 


\section{Acknowledgments}

We are thankful to Dr H. H. Shah, The Dean, M. P. Shah, Medical College, Jamnagar, for allowing us to publish this paper. We are indebted to $\mathbf{M} / \mathrm{S}$ Ranbaxy Laboratories Private Ltd, New Delhi, for generous supplies of diazepam (Calmpose). We are also thankful to Mr Dilip Shah, College Statistician, for his help.

\section{References}

Arrigo, A., JanN, G. \& Tonali, P. (1965) Some aspects of the action of valium and of librium on the electrical activity of the rabbit brain. Archives internationales de pharmacodynamie et de thérapie, 154, 364.

BRADLEY, T.B. \& KEY, J.B. (1958) The effect of drugs on the arousal responses produced by electrical stimulation of the reticular formation of the brain. Electroencephalogy and Clinical Neurophysiology, 10, 97.

Brown, B.B. \& WERner, H.W. (1954) Pharmacologic studies on the new central stimulant $\alpha$-(2-piperidyl) benzhydrol and hydrochloride (MRD-108). Journal of Pharmacology and Experimental Therapy, 110, 180.

DAS, A.K., GuPTA, R.K. \& DE, S. (1967) Diazepam in tetanus. Journal of the Indian Medical Association, 49, 130.

Domino, E.F. (1965) Drill's Pharmacology in Medicine (Ed. by J. R. Di Palma), Third edition, p. 360. McGraw-Hill: New York.

Femi-Pearse, D. (1966) Experience with diazepam in tetanus. British Medical Journal, 2, 862.
Grewal, R.S. \& Sharma, B.K. (1969) Valium in the treatment of tetanus. Indian Practitioner, $22,643$.

Hendrickse, R.G. \& Sherman, P.M. (1965) Therapeutical trial of diazepam in tetanus. Lancet, $\mathbf{i}, 737$.

Hendrickse, R.G. \& Sherman, P.M. (1966) Tetanus in childhood: report of therapeutic trial of diazepam. British Medical Journal, 2, 860.

Hernandez-Peon, R., Rojas-Ramirez, J.A., O'Flaherty J.J. \& Nuzzuchelli-O'Flaherty, A.L. (1964) An experimental study of the anticonvulsive and relaxant activities, of valium. International Journal of Neuropharmacology, 3, 405.

LAHA, P.N. \& VAIShYA, P.D. (1965) Tetanus: a study of 1000 cases. Journal of the Indian Medical Association, 44, 422.

Patel, J.C. \& Joag, G.G. (1959) Grading of tetanus to evaluate prognosis. Indian Journal of Medical Sciences, 13, 834.

Randall, L.O., Heise, G.A., Schallek, W., Bagdon, R.E., Banziger, R., Boris, A., Moe, R.E. \& Abrams, W.B. (1961) Pharmacology and clinical studies on valium. A new psychotherapeutic agent of the benzodiazepine class. Current Therapeutic Research, 3, 405.

VAN HeIJsT, A.N.P. (1970) Tetanus. Nederlands tijdschrift voor geneeskunde, Amsterd am, 114, 9.

WeINBERG, W.A. (1964) Control of the neuromuscular and convulsive manifestations of severe systemic tetanus. Clinical Pediatrics, 3, 226. 